\title{
An Investigation into Metacognitive Strategy Use in Reading among Chinese Non-English Majors
}

\author{
Shang Chen \\ School of Foreign Language, Wuhan Institute of Technology, Wuhan, Hubei Province, China \\ shangwen057@163.com
}

\begin{abstract}
The present study is designed to investigate the overall situation of the metacognitive strategies employed in reading by foreign language learners. The subjects of this study were 160 non-English major freshmen from Wuhan Institute of Technology. Data were collected through the questionnaire, and analyzed in SPSS 16.0. Descriptive analysis were employed to do the data analysis. The paper aims to answer the following questions: 1 . whether the students are proficient at using metacognitive strategies in English as a second language reading? 2. Which metacognitive strategies are used more often? The results showed that students demonstrate different proficiency of the use of metacognitive strategies in reading practice. The planning strategies are the most frequently used.
\end{abstract}

Keywords: reading; metacognitive strategies.

\section{Introduction}

In second language acquisition, reading is important for language learners. It is the major method for language learners to learn about a language and increase their knowledge about the target language culture. With the globalization of the world, Chinese students have more access to the English materials. Since most of the materials are in written form, Chinese students can get more information about the culture of English-speaking countries through extensive reading.

In reading, many learning variables are considered to influence the proficiency of reading. Metacognitive strategy has a significant impact on second language reading proficiency. The present study is designed to investigate the overall situation of metacognitive strategies employed in reading by second language learners.

\section{Literature Review}

Studies on metacognitive strategies used in second language learning have become a heated area for researchers. They conduct studies on the second language learners' beliefs, gender and proficiency, attempt to find out their relationship with metacognitive strategies.

O'Malley and Chamot (1990:138) use the think-aloud methodology to find out there are certain relationship between metacognitive strategies and language learner's proficiency. Carrell (1989) investigated the metacognitive awareness of second language readers about reading strategies and concluded that lower proficiency levels readers used more bottom-up strategies. Ehrman and Oxford (1989), Bacon (1992) have found out the females have a higher metacognitive using level than males. Vandergrift (1997b) found out that females use metacognitive strategies more frequently than males. Wen Qiufang (1996a, 1996b) and Li Jiongying (2002) have studied the correlation between language learner's beliefs and metacognitive strategies use. Wang Duqin (2002) studies the effects of metacognitive strategy training in fostering learner autonomy. He found metacognitive strategies can encourage language learners to manage their learning process. Li Lan (2005) conducts metacognitive strategies training in English class. The results of these training suggest it can help students manage their English learning, and also improve their language performance. Hu Yang and Zhang Weimin (2006) do a research on the ability of using metacognitive strategies. The results show metacognitive strategies ability can be improved by class training. Li Jun and Ni Hangying (2007) conduct a case study by means of interventional research. The study proves that students with low English proficiency can be good at English learning if they master the metacognitive strategies. 


\section{Design and Method}

\subsection{Subjects}

The subjects participating in this study are 160 non-English freshmen of Grade 2014 randomly selected from Wuhan Institute of Technology. They are under the same English course design and are taught by the same English teacher.

They are chosen from 6 intact classes and major in a variety of specialties. According to the requirement of the research, we need to pick out the students with the same reading level. Based on the teacher's observation and their reading scores of the final exam, the top $25 \%$ of the students and the weakest $25 \%$ were eliminated. The middle $50 \%$ of the students were chosen as the subjects, the number of whom is 80 , and were to take part in the survey.

Their age ranges from 18 to 20 with the average of 18.7. All the subjects have learned English as a required school course during middle school, and taking nearly one year of college English courses, most of them learned English for almost seven years.

\subsection{Research questions}

The following research questions are going to be explored:

1. Whether the students are proficient at using metacognitive strategies in English as a second language reading?

2. Which metacognitive strategies are used more often?

\subsection{Instruments}

The instrument used in the study is a questionnaire about metacognitive strategies employed in English reading. In this questionnaire, according to O'Mally and Chamot's classification, metacognitive strategies are classified into 3 groups: planning, self-monitoring and self-evaluation. The questionnaire is a self-scoring survey with 5-point scale. The score of the questionnaire indicates the level of the metacognitive strategy use in reading. The higher the score is, the higher the level of the metacognitive strategy use in reading.

\subsection{Data collection}

The questionnaires were delivered to the subjects at the beginning of the English class. Before the subjects got the questionnaire, they were informed of the purpose of the questionnaires, which is to do academic research, and their response to it would not affect their course grade. In this case, the objectiveness of the questionnaires is guaranteed. 20 minutes later, the questionnaires were collected, 80 pieces of questionnaire sheets delivered were returned altogether, so all 80 pieces were proved to be valid. Data from the questionnaires were typed into the computer as the raw data and analyzed through SPSS16.0.

\section{Results and Discussions}

Talbe 1 Descriptive statistics for metacognitive strategy use in reading

\begin{tabular}{|c|c|c|c|c|c|}
\hline & $\mathrm{N}$ & Minimum & Maximum & Mean & Std. Deviation \\
\hline Total score & 80 & 66.00 & 135.00 & 98.07 & 16.03 \\
\hline The least proficient & 18 & 66.00 & 81.00 & 75.12 & 5.24 \\
\hline The average proficient & 46 & 84.00 & 111.00 & 99.89 & 8.17 \\
\hline The most proficient & 16 & 114.00 & 135.00 & 120.06 & 6.59 \\
\hline Valid N (listwise) & 16 & & & & \\
\hline
\end{tabular}

As is shown in Table 1, the mean score of the overall metacognitive strategy use is 98.07, which indicate a moderate use of metacognitive strategy. Students show different proficiency in metacognitive strategy use. Most of the students have an average proficiency with the mean score of 
99.89. Only 16 students belong to the most proficient group with the mean score of 120.06 and the other 18 students fall into the least proficient group.

The results tell us that Students have developed a certain proficiency of using metacognitive strategies in English reading, but this average proficiency is still not satisfactory. Most students can use the metacognitive strategies moderately in reading. Only a few students can use them proficiently.

Next, the author sets about solving the second problem: Which metacognitive strategies are used more often?

Table 2 statistics for metacognitive reading strategy use

\begin{tabular}{|c|c|c|c|}
\hline categories & $\begin{array}{c}\text { Mean } \\
\text { (item) }\end{array}$ & Std.Deviation (item) & Rank order of usage \\
\hline Planning strategies & 2.89 & 0.54 & 1 \\
\hline Self-monitoring strategies & 2.81 & 0.41 & 2 \\
\hline Self-evaluating strategies & 2.43 & 0.66 & 3 \\
\hline Overall & 2.72 & 0.44 & \\
\hline
\end{tabular}

As shown in Table 2, the item mean score of planning strategies rank the highest, and the item mean score of Self-evaluating strategies is the lowest. So the Planning strategies are the most frequently used. Setting reading goals, choosing proper reading materials and using reading strategies are the main components of planning reading strategies, the awareness of the importance of setting reading goals enables the learners to have a good performance in each step of the learning activities.

\section{Conclusion}

Most of the non-English majors under investigation have developed certain abilities of using metacognitive strategies but some are still deficient in this aspect. The metacognitive strategy that they employ most is planning strategies. There also exist differences in connection with the students' metacognitive strategy proficiency.

Based on these results, it is suggested that teachers should conduct metacognitive training among students to enhance the awareness of metacognitive strategies. Thus, students are sure to improve their reading proficiency with some metacognitive knowledge during the reading process.

However, the limitations in present study is that other influencing variables, such as personality, gender, motivation and learning style are not included in this study. Future researches could take more influential variables into consideration.

\section{References}

[1] Bacon, S. 1992. The Relationship between Gender, Comprehension, Processing Strategies, and Cognitive and Affective Response in Second-Language Listening [J]. The Modern Language Journal. 76:160-78.

[2] Carrell, P. L. 1989. Metacognitive awareness and second language reading [J]. Modern Language Journal, 73,ii. 121-131.

[3] Ehrman M. and R. Oxford. 1989. Effects of Sex Differences, Career Choice, and Psychological Type on Adult Language Learning Strategies[J]. The Modern Language Journal, 73:1-13.

[4] O’Malley, J. M. and Chamot, A. U. 1990. Learning Strategies in Second Language Acquisiton[M]. Cambridge: Cambridge University Press.

[5] Vandergrift, L. 1997b. 'The Strategies of Second Language (French) Listeners: A Descriptive Study’. Foreign Language Annuals, 30 (3): 387-409. 